\title{
Planarian GSK3s are involved in neural regeneration
}

\author{
Teresa Adell • Maria Marsal • Emili Saló
}

Published online: 30 January 2008

(C) Springer-Verlag 2008

Erratum to: Dev Genes Evol (2008)

DOI 10.1007/s00427-007-0199-3

The original version of this article unfortunately contained a mistake in Fig. 4h. The correct version is given here.

(It must read anti-tubulin instead of anti-synapsin)

The online version of the original article can be found at http://dx.doi.org/ 10.1007/s00427-007-0199-3

T. Adell $(\bowtie) \cdot$ M. Marsal $\cdot$ E. Saló $(\bowtie)$

Departament de Genètica, Facultat de Biologia,

Universitat de Barcelona, Diagonal 645,

08028 Barcelona, Spain

e-mail: tadellc@ub.edu

e-mail: esalo@ub.edu 

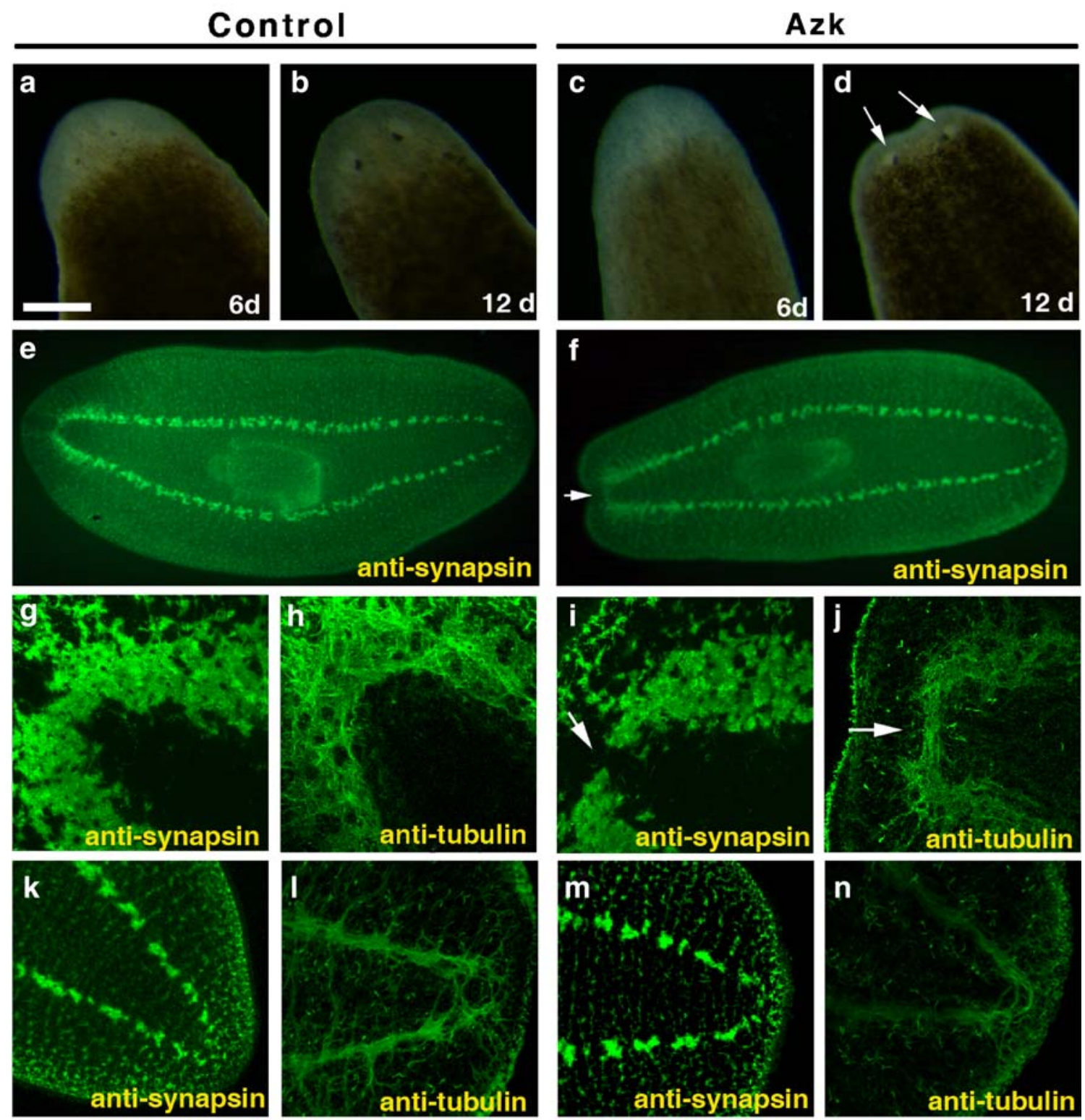

Ami
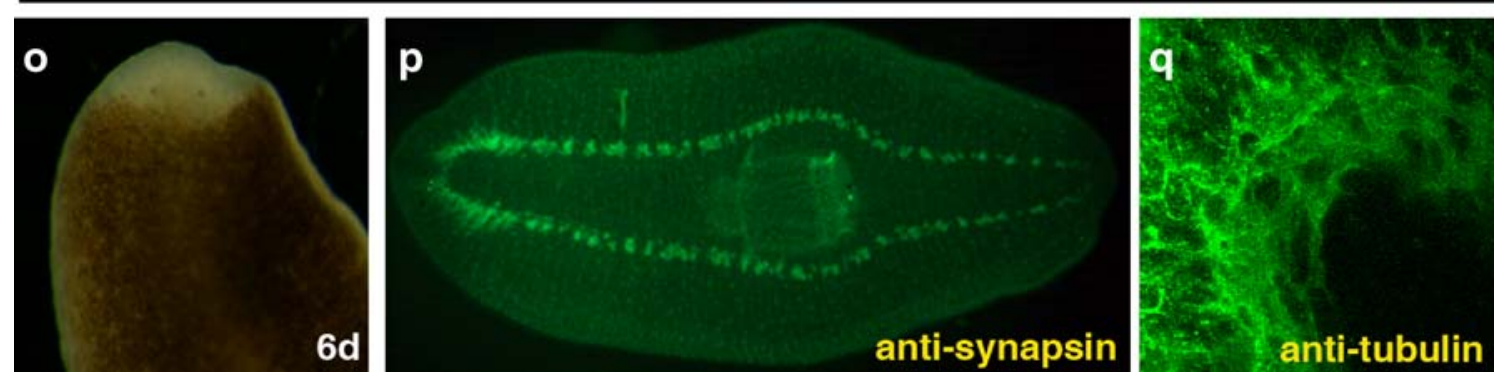